\title{
Open Access Examples in Theology
}

Guides to Open Access Resources in Theology and Religion

- Yale University Library

https://guides.library.yale.edu/c.php?g=295851\&p=1972637

- Duke University Libraries

https://guides.library.duke.edu/c.php?g=289800\&p=1931313

- Australian Catholic University

https://libguides.acu.edu.au/theology/openaccess

ATLA

- ATLA Publications moving to open access https://www.atla.com/about/pressroom/Pages/ATLA-

Publications-Moving-to-Open-Access.aspx

- ATLA Press Open Access monographs (launched 2014) https://books.atla.com/atlapress/catalog

Luther Seminary

- Open Access Policy https://luthersem.libguides.com/oapolicy

Institutional Repositories and Digital Archives

An open access repository is a set of services that provide open access to research or educational content created at an institution or by a specific research community. 
- University of Divinity https://repository.divinity.edu.au/ (EPrints 3 software)

- Moore Institutional Repository https://myrrh.library.moore.edu.au/ (DSpace software)

- Avondale Institutional Repository https://research.avondale.edu.au// (Digital Commons bepress)

- ACU ResearchBank http://researchbank.acu.edu.au// (Digital Commons bepress)

- Luther Seminary http://digitalcommons.luthersem.edu/about.html (Digital Commons bepress)

- Princeton https://archive.org/details/Princeton; http://journals.ptsem.edu/

- Directories: OpenDOAR http://v2.sherpa.ac.uk/opendoar/ ; ROAR http://roar.eprints.org/

- PhilArchive - https://philarchive.org/

- Australian Institutional Repositories - https://aoasg.org.au/open-access-repositoriesat-australian-institutions/

- SUNScholar/Practical guidelines for starting an institutional repository (IR) http://bit.ly/goodir

\section{OA Search Engines and Browser Extensions}

- Browser Extensions to find OA content

- Unpaywall http://unpaywall.org/

- Open access button https://openaccessbutton.org/

- Google Scholar

- Lazy Scholar http://www.lazyscholar.org/

- Kopernio https://kopernio.com/ (Clarivate Analytics. Registration required)

- Free OA Search engines

- EmbedOA https://openaccessbutton.org/embedoa

- lfindr https://lfindr.lscience.com/home/

- CORE https://www.jisc.ac.uk/core CORE (Jisc)

- Google Scholar https://scholar.google.com.au/

- Humanities Commons https://hcommons.org/

- Open Archive of the Social Sciences https://socopen.org/ 
- Directory of Open Access Journals https://doaj.org/

- Directory of Open Access Books https://www.doabooks.org/

\section{Useful Links}

- Australian Open Access Strategy Group https://aoasg.org.au/ AOSG works to advocate, collaborate, raise awareness, lead and build capacity for open access to all the outputs of scholarship in Australia and New Zealand.

- SPARC https://sparcopen.org/ Global coalition committed to making Open the default for research and education.

- SHERPA/RoMEO http://www.sherpa.ac.uk/romeo/ Use this site to find a summary of permissions that are normally given as part of each publisher's copyright transfer agreement.

- Creative Commons Licenses http://creativecommons.org/licenses/ An outline of the various CC licenses that cater for the various access and re-use wishes of copyright owners. Offering your work under a Creative Commons license does not mean giving up your copyright; it means permitting users to make use of your material in various ways, but only under certain conditions.

- OpenDOAR - Directory of Open Access Repositories http://v2.sherpa.ac.uk/opendoar/ Quality-assured, global directory of academic open access repositories. Search for open access academic, peer-reviewed books.

- Harvard Open Access Project https://cyber.harvard.edu/hoap/Main_Page HOAP consults with universities, funding agencies, publishers, museums and other institutions developing $O A$ policies and refining $O A$ practices. Includes 'Good practices for university open-access policies'.

- Think, Check, Submit https://thinkchecksubmit.org/ A simple checklist researchers can use to assess the credentials of a journal or publisher. 


\section{Green Open Access (self-archiving)}

- Publishing article in a subscription based journal and then depositing author accepted copy in a freely accessible institutional/disciplinary repository

- Archiving: author accepted version (post-print) to institutional/disciplinary repository

- Open Access usually after a set embargo period

- SHERPA/RoMEO site provides publisher copyright policies on self-archiving

\section{GREEN OPEN ACCESS}

increased dissemination, economic efficiency \& social impact

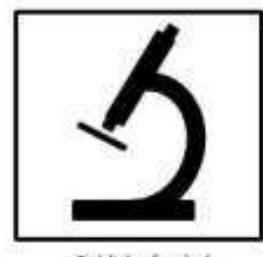

Publicly funded researchers conduct research and write up results.

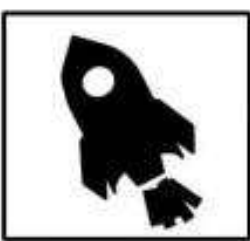

Accelerated scientific progress \& increased return on public investment.

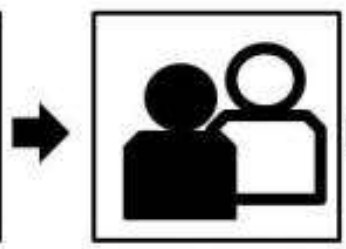

Manuscripts submitted to subscription journals \& reviewed by peers.

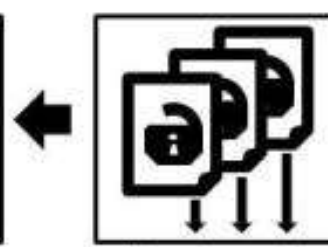

After embargo period, pubitic can download the open access coples from repositories.

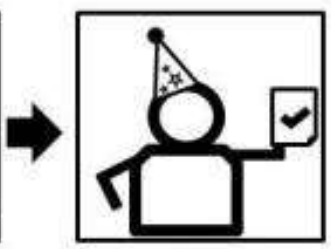

Manuscripts accepted for publication.

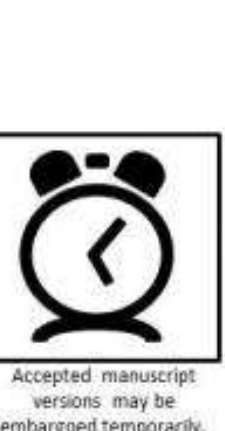

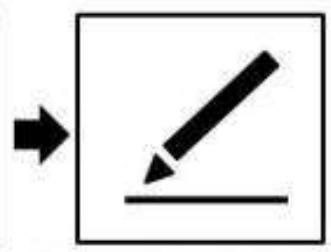

Authors assign copyright to publishers, but retain the right to disseminate an OA cop: (of the accepted manuscript) via open access repositorles.

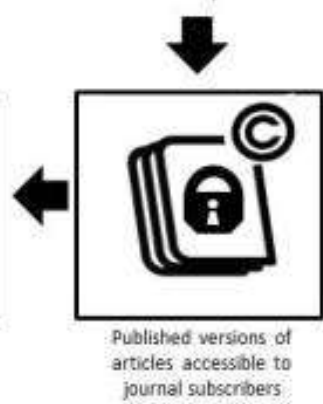

immediately.

Paibo Casan 3 Sarah Brown, CuT 2014 CC-AY 4 


\section{Gold Open Access (publishing in an OA journal)}

- Publishing in an open access journal

- Open access to public immediately upon publication (often under CC open licenses)

- Archiving: version of record (print PDF from publisher)

- Authors may be required to pay an Article Processing Charge (between \$1000-\$5000)

\section{GOLD OPEN ACCESS}

maximised dissemination, economic efficiency \& social impact

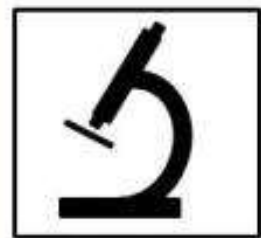

Publicy funded researchers conduct research and write up results.

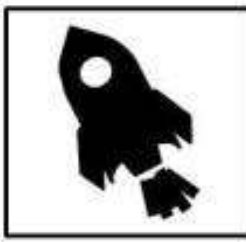

Accelerated scientific progress \& maximised return on public investment.

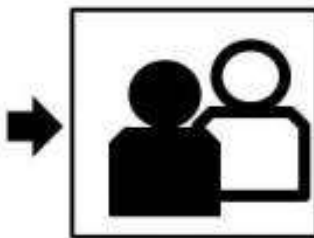

Manuscripts submitted to Open Access journals \& reviewed by peers.

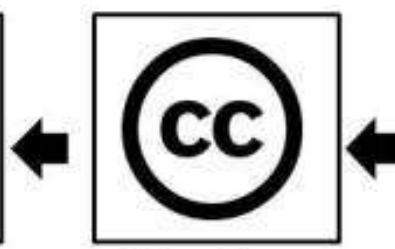

Public granted reuse rights under open licenses:

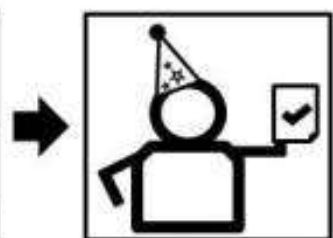

Manuscripts accepted for publication.

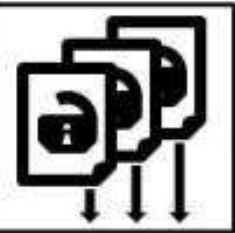

Published versions of articles immediately accessible to public.
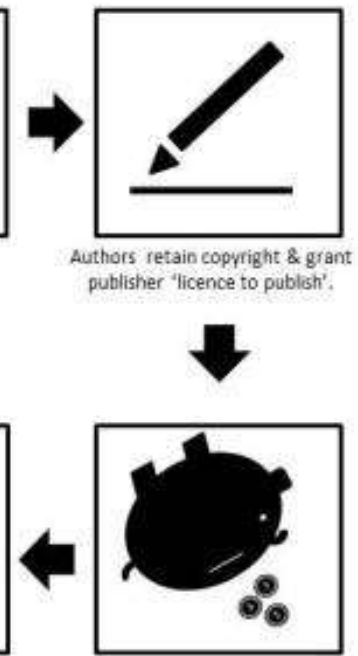

Autbors may be required to pay publisher an 'articleprocessing charge' to cover publishing cost5

SOURCE: Australasian Open Access Strategy Group (2013). What is open access https://aoasg.org.au/what-isopen-access/ 